\title{
International cooperation group of emergency surgery during the COVID-19 pandemic
}

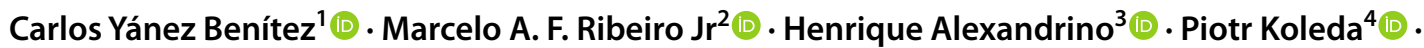

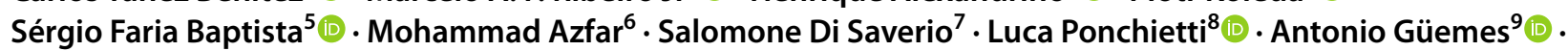 \\ Juan L. Blas ${ }^{1}\left[\right.$. Carlos Mesquita ${ }^{3}$
}

Received: 19 July 2020 / Accepted: 26 September 2020 / Published online: 13 October 2020

c) Springer-Verlag GmbH Germany, part of Springer Nature 2020

\begin{abstract}
Purpose The COVID-19 pandemic has changed working conditions for emergency surgical teams around the world. International surgical societies have issued clinical recommendations to optimize surgical management. This international study aimed to assess the degree of emergency surgical teams' adoption of recommendations during the pandemic.

Methods Emergency surgical team members from over 30 countries were invited to answer an anonymous, prospective, online survey to assess team organization, PPE-related aspects, OR preparations, anesthesiologic considerations, and surgical management for emergency surgery during the pandemic.

Results One-hundred-and-thirty-four questionnaires were returned $(N=134)$ from 26 countries, of which $88 \%$ were surgeons, $7 \%$ surgical trainees, $4 \%$ anesthetists. $81 \%$ of the respondents got involved with COVID-19 crisis management. Social media were used by $91 \%$ of the respondents to access the recommendations, and $66 \%$ used videoconference tools for team communication. 51\% had not received PPE training before the pandemic, 73\% reported equipment shortage, and 55\% informed about re-use of N95/FPP2/3 respirators. Dedicated COVID operating areas were cited by $77 \%$ of the respondents, $44 \%$ had performed emergency surgical procedures on COVID-19 patients, and over half (52\%), favored performing laparoscopic over open surgical procedures.

Conclusion Surgical team members have responded with leadership to the COVID-19 pandemic, with crisis management principles. Social media and videoconference have been used by the vast majority to access guidelines or to communicate during social distancing. The level of adoption of current recommendations is high for organizational aspects and surgical management, but not so for PPE training and availability, and anesthesiologic considerations.
\end{abstract}

Keywords Coronavirus infections $\cdot$ Pandemic $\cdot$ Personal protective equipment $\cdot$ Surgery $\cdot$ Patient care team

$\begin{array}{ll}\text { Abbreviations } \\ \text { COA } & \text { COVID operating areas } \\ \text { ICU } & \text { Intensive Care Unit } \\ \text { OR } & \text { Operating room } \\ \text { OTI } & \text { Orotracheal intubation } \\ \text { PPE } & \text { Personal protective equipment } \\ \text { Po/PACU } & \text { Preoperative-Postoperative Anesthesia } \\ & \text { Care Unit } \\ \text { RSI } & \text { Rapid sequence induction } \\ \text { RT-PCR } & \text { Reverse transcriptase-polymerase chain } \\ & \text { reaction }\end{array}$

Carlos Yánez Benítez

carlosyb1@gmail.com; cjyanezb@salud.aragon.es

Extended author information available on the last page of the article
SARS-CoV-2 Severe Respiratory Syndrome Coronavirus 2

WHO World Health Organization

\section{Introduction}

In December of 2019, the world learned about the emergence of a new coronavirus outbreak, this time in Wuhan, Hubei province, China. Initially termed 2019 novel coronavirus (2019-nCoV), it would be known worldwide as the Severe Acute Respiratory Syndrome coronavirus 2 (SARSCoV-2) [1]. This new disease was termed as COVID-19 and spread rapidly worldwide. On March 11, 2020, the World Health Organization (WHO) declared the disease caused by the SARS.CoV-2 a worldwide pandemic [2]. The high 
transmissibility of the SARS-CoV-2 and the overwhelming magnitude of this pandemic forced surgery teams to reexamine workflow, organization, and management for surgical emergency cases [3]. These unprecedented challenges imposed swift changes to avoid the collapse of the health system and the workforce's compromise [4]. To prepare surgical teams for this infectious mass casualty scenario, several international surgical and anesthesia societies produced guidelines on emergency surgery, focusing on preventing the infection of its workforce and guarantee the best response [5-13]. These COVID-19 dedicated protocols addressed surgical team organization, operating room (OR) preparation, rational use of personal protective equipment (PPE), considerations on anesthesiology, and intraoperative management of emergency surgical pathology. Several articles have been published focusing on the technical surgical aspects during the pandemic and surgical ward preparations [14-17]. However, fewer have put the spotlight on individual countries' responses [18], and none that we know have assessed the level of adoptions of current recommendations at an international level. This study aimed to obtain a global snapshot of the level of implementation of these new recommendations by the members of the international emergency surgery community during the COVID-19 pandemic.

\section{Methods}

An International Cooperation Group of Emergency Surgery during the COVID-19 pandemic was formed with surgeons from Brazil, Chile, Italy, Portugal, and Spain to study the pandemic's impact on emergency surgery teams at the international level. The group used the SurveyMonkey ${ }^{\circledR}$ platform to develop a five-section structured questionnaire in English that assessed the adoption of updated recommendations for emergency surgery during the COVID-19 pandemic. No specific identifying data were requested, six questions queried about demographic information, seven about team organization, 25 regarding PPE, 21 OR adequation, anesthesia considerations, and surgical management.

The questions were presented in such a way that respondents could agree or disagree with the specific statements. The online survey was issued prospectively, anonymously and voluntarily, from the 1st to the 14th of April 2020, to 680 members of emergency surgical teams from over 30 countries. The survey target population was selected using a non-probability method consisting of a convenience sample of five significant surgeons' associations, which included professionals ascribed to the Spanish Surgical Association, European Society for Emergency and Trauma Surgery, International Association for Trauma Surgery and Intensive Care, American College of Surgeons, and the Panamerican Trauma Society. Subjects were invited through email invitations, mailing lists of some participating societies, and posted via personal networks and social media. Survey results were analyzed using the SurveyMonkey ${ }^{\circledR}$ online platform (SVMK Inc, San Mateo, USA), calculating frequencies and percentages of the collected data.

\section{Results}

A total of 134 valid responses from 26 countries were obtained from 680 (20\%) of the issued invitations, of which $119(88 \%)$ were surgeons, $9(7 \%)$ surgical trainees, and 6 (4\%) anesthetists. The vast majority were males (72\%), with ages ranging from 25 to over 60 . Respondents worked in 26 different countries, mostly from Europe, with 85 responses from 8 different countries, followed by 42 responses from 12 American countries, five from four countries in the Middle East, and two countries from Asia, with one response each Fig. 1.

\section{Surgical team organization}

$81 \%$ of the respondents got involved with the COVID19 surge planning taskforce, 93 (71\%) developing clinical protocols, 91 (69\%) implementing safety precautions, and 67 (51\%) performing task management. Social media and other online resources were employed by $122(91 \%)$ respondents to obtain relevant COVID-19 clinical guidelines Fig. 2. Modification of shift handover routines and the use of video conference tools, to maintain communication

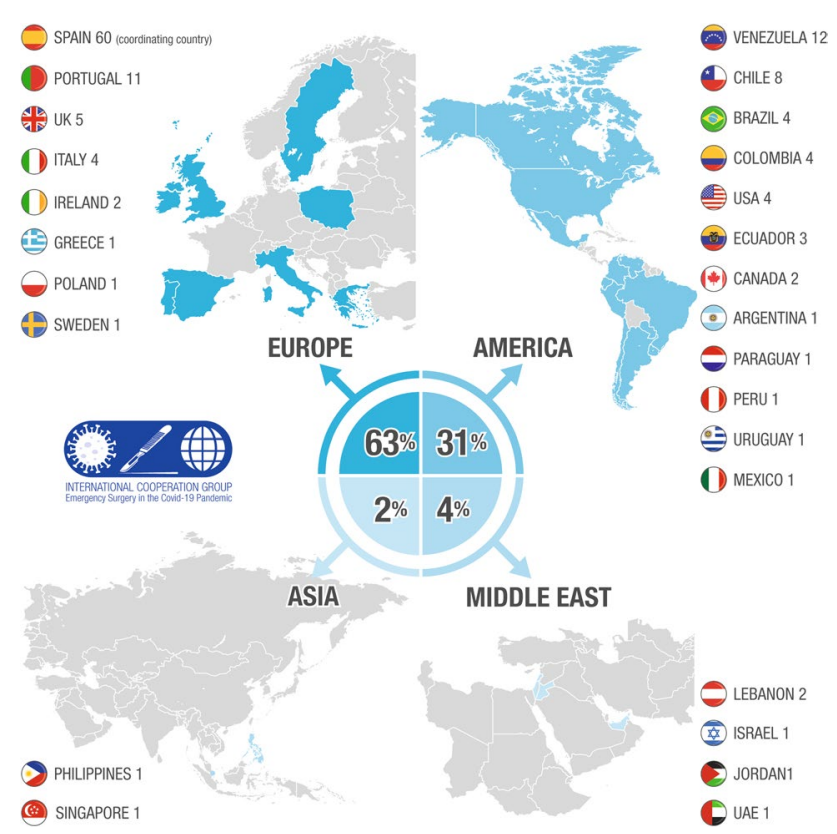

Fig. 1 Respondents $(N=134)$ by region and country 


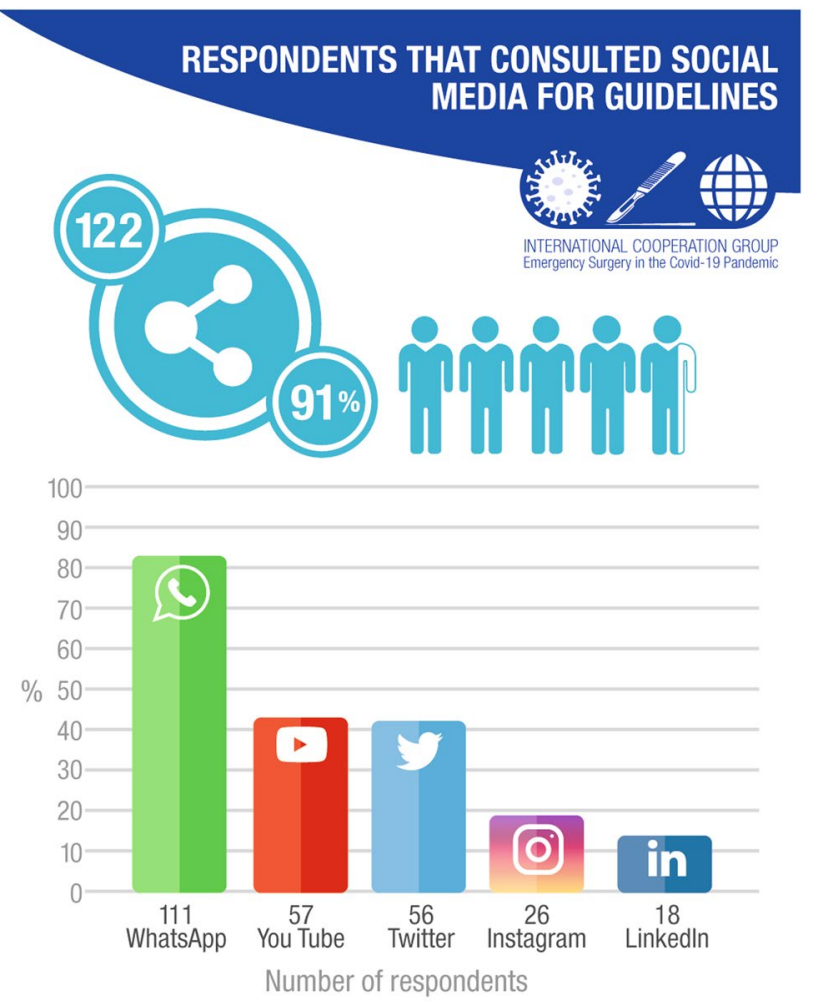

Fig. 2 Participants' use of social media channels

while promoting social distancing within the working place, was reported by 88 (66\%) of them Fig. 3. Continuity performing their regular tasks was reported by 73 (54\%) of the respondents, in contrast with the rest, whose newly assigned duties were to the emergency department COVID-19 triage (25\%), the intensive care unit (ICU) activities (13\%), or had to manage mechanically ventilated patients in the surgical ward $(7 \%)$. Another modification to their routines was in shift duration, as reported by $80(60 \%)$, and over half of the total (52\%) worked continuously for extended periods of $24 \mathrm{~h}$ or more.

\section{Personal protective equipment (PPE)}

About half (51\%) of the respondents had not received training in the use of PPE for airborne infectious risk while performing emergency surgical procedures before the pandemic, and roughly over one-third (37\%) had it during the studied period. Of all the respondents, $105(78 \%)$ used surgical masks, and 38 (28\%) wore N95/FPP2/3 respirators always in the ward, even without COVID-19 hospitalized. Over half (56\%) had a specific area assigned for donning/ doffing the PPE, 53\% employed checklist, and 60\% performed routine buddy checks. Three-fourths (75\%) made mask fit tests while donning, one-third (34\%) reported that fitting issues due to facial hair (beard), and out of these,

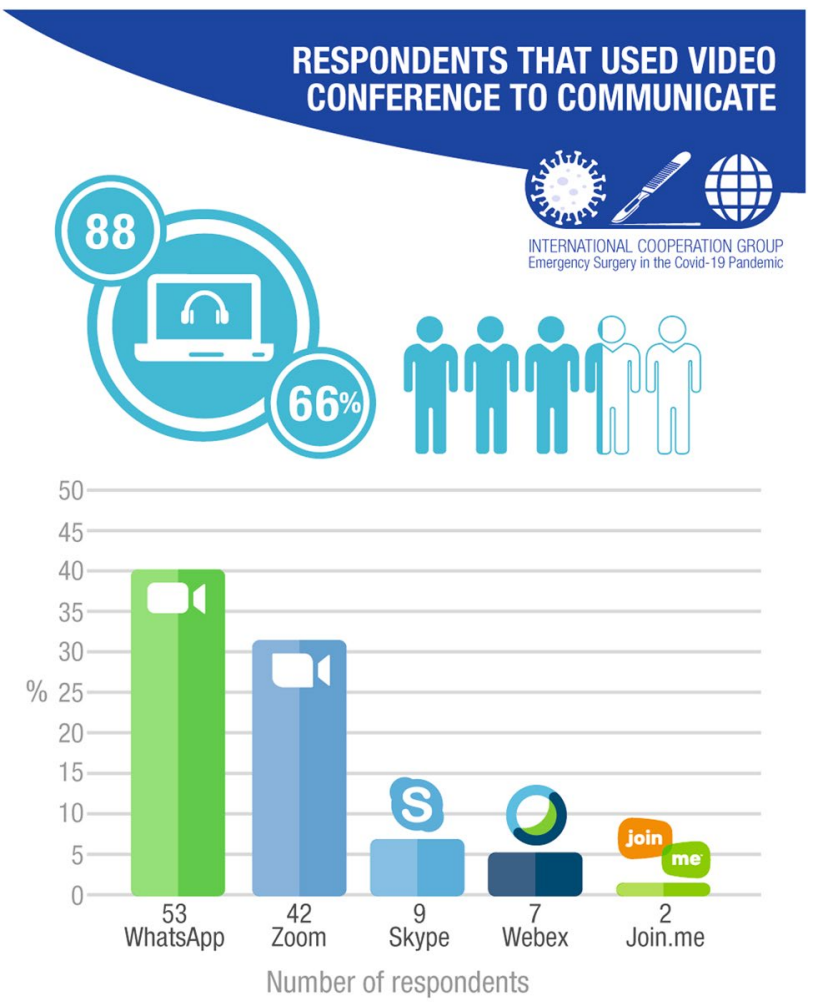

Fig. 3 Participants' use of video conference tools

half $(51 \%)$ shaved it to obtain an adequate fit. The reported PPE used for emergency procedures was face shield (74\%), double gloving (71\%), surgical goggles (68\%), long sleeve disposable gown (63\%), and water-resistant shoe covers (35\%) Fig. 4. Data about the shortage of PPE (73\%) and N95/FPP2/3 (77\%), as well as the re-use of PPE components (55\%), were collected Fig. 5. Reuse or extended use of N95/ FPP2/3 beyond the lapse they were designed for was commented by $55 \%$ of the respondents Fig. 5. Scarcity or even absence of parts of such equipment was reported by $53 \%$ Fig. 6.

When asked if using PPE gave a sense of protection during the surgical procedure, less than half (48\%) of the respondents felt protected with PPE.

\section{Operating room preparations}

Over three-fourths (77\%) of the participants had COVID operating areas (COA), OR facilities prepared or modified for performing emergency surgery in COVID-19 patients, and over two-thirds (69\%) had a designated COVID-19 trauma OR. The vast majority $(80 \%)$ cleared out unnecessary equipment form the OR when performing surgery on COVID-19 patients, and 78 (60\%) protected monitors and other electronic equipment, including anesthesia machine, with plastic wraps; $70 \%$ used OR alert signs during the 


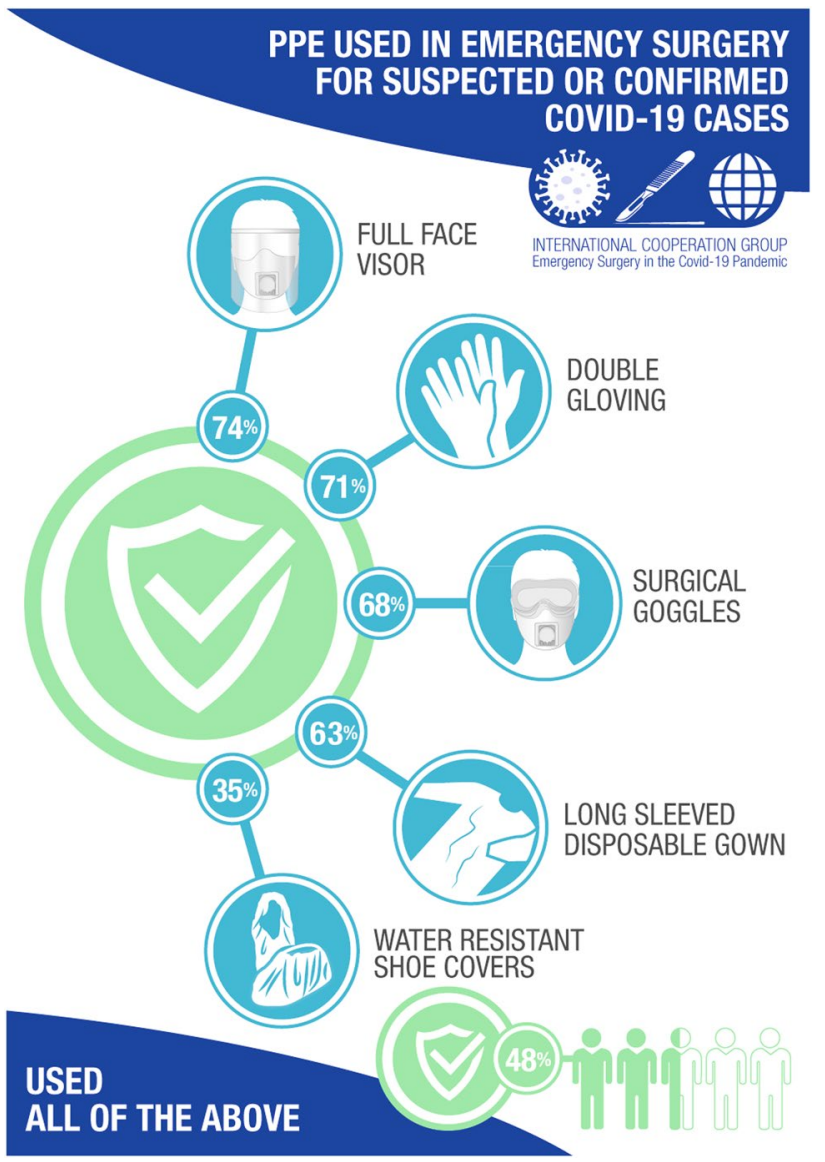

Fig. 4 Personal protective equipment used for emergency surgery

procedure in COVID-19-positive or suspected cases. However, only over one-fourth (26\%) had surgical smoke evacuation systems available, and above two-fifths (43\%) had to improvise such a device.

\section{Anesthesiologic equipment considerations}

When asked about the transport of emergency surgical cases to the OR, almost two-thirds (64\%) answered that COVID19 emergency surgical cases were escorted directly to the OR, not stopping in the Preoperative-Postoperative Anesthesia Care Unit (Po/PACU). Regarding anesthesiologic equipment preparations, less than half (40\%) had a COVID-19 resource box available for general anesthesia procedures (including cheat sheets and alert signs). Only one-fourth (25\%) said to have a specific COVID-19 airway trolley at their institution, and of these, $27 \%$ had access to a printed intubation guideline. Over one-third (38\%) responded that the anesthesia team routinely used video laryngoscopy for orotracheal intubation (OTI), and almost two-thirds did not know if rapid sequence induction (RSI) was the induction protocol used.

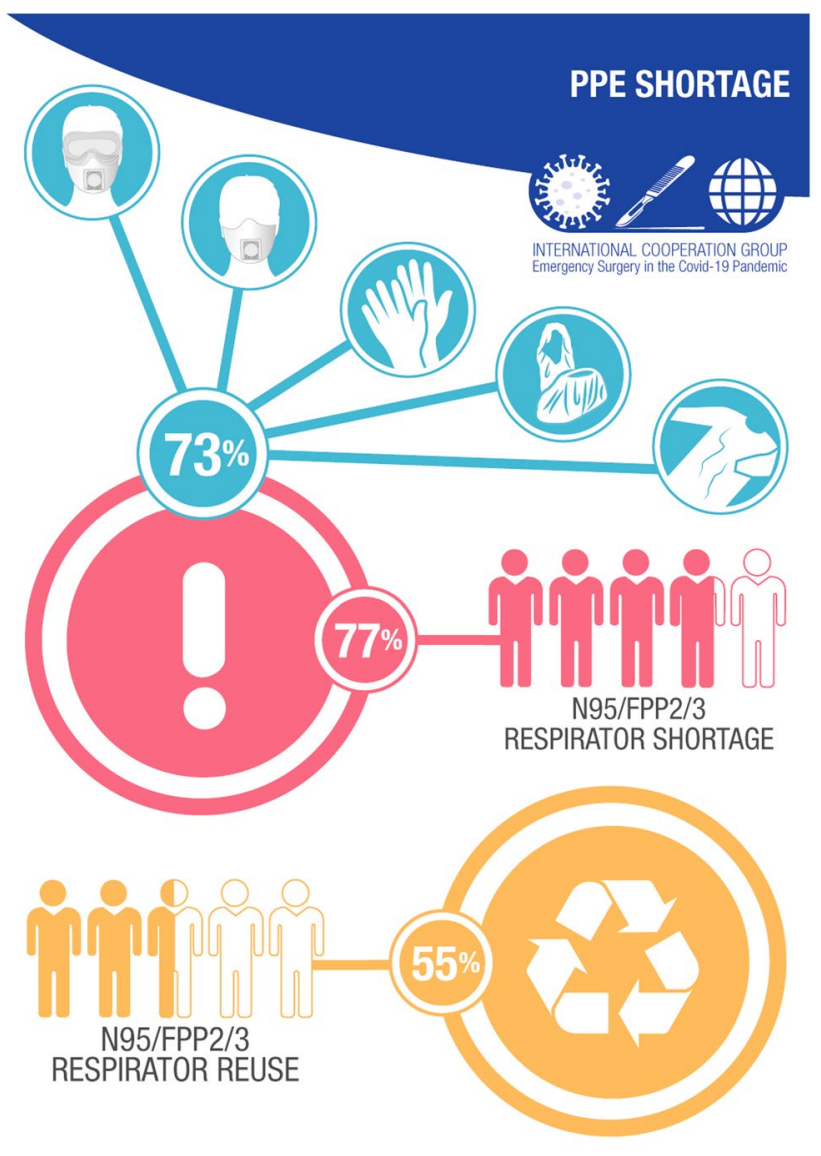

Fig. 5 Shortage of Personal protective equipment for emergency surgical procedures

\section{Emergency intraoperative management}

Almost two-thirds used a COVID-19-specific checklist before surgery, and an equal number of respondents entered the OR after patient intubation. Less than half (44\%) had performed emergency surgical procedures on COVID-19 patients during the study, and only over one-fourth, 26\% had performed emergency laparoscopic surgery on these patients. However, when asked which approach was preferred for acute appendicitis or cholecystitis, over half (52\%), preferred the laparoscopic approach. When asked for preoperative screening methods, only one-third (32\%) systematically performed COVID-19 screening before emergency surgery. $50 \%$ of these used the reverse transcriptase-polymerase chain reaction (RTPCR) test, the rest recurred to radiological screening, either thoracic CT scans (14\%) or lung US (1\%). When asked for the number of emergency cases evaluated in the emergency department, the vast majority $(82 \%)$ perceived a lower frequency of emergency surgical emergencies during the studied period. 


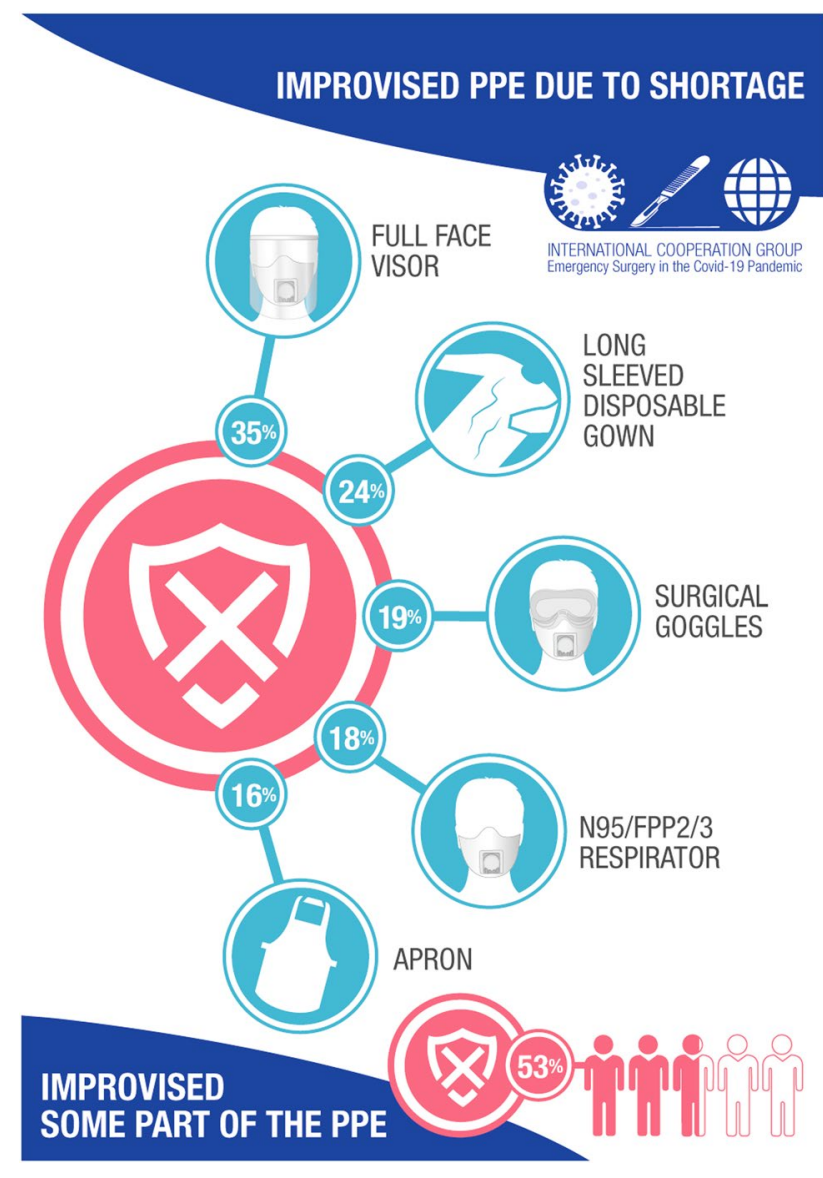

Fig. 6 Improvisation of personal protective equipment in emergency surgery

\section{Discussion}

While the novelty of this pandemic has generated many published papers on management recommendations [19-23], few assess the degree of guidelines implementation by emergency surgical teams. This study provides an international snapshot of the level of adoption of the guidance for surgical team organization, adequacy of PPE availability and usage, OR preparation, anesthesiologic considerations, and intraoperative management of emergency surgical cases during 2 weeks of the COVID-19 pandemic. It should be noted that the study tried to capture the initial response when there was a steep curve of newly reported cases, but while that was the case in Europe at the time of the survey, the American surge came weeks later. The study analyzed the recommendations for emergency surgical management of COVID-19 suspected or confirmed cases, which may differ significantly between countries due to the variability of the number of newly diagnosed cases, resources available, and healthcare policies. Increased awareness and adoption of international societies' recommendations for emergency surgical management with greater exposure to COVID-19 were expected amongst surgeons with higher case exposure, but the study design did not allow this assumption. Nonetheless, the study can help identify weaknesses in the surgical team response and areas of improvement, which could be useful to face the latest news that brings up attention like the possibility of a second wave of the pandemic [24-26].

Regarding the surgical teams' organization, most of the published literature focuses on reducing the risk of infection by limiting the number of workforce members on each procedure [2, 27]. Furthermore, the emphasis is made on rescheduling elective surgical procedures to rationalize hospital bed capacity. However, few mention surgical teams' leadership organizing the response to the pandemic [28]. We found out that over $80 \%$ of the teams' members have been doing so, either developing protocols $(71 \%)$ and implementing safety precautions (69\%), which confirms the capacity of emergency surgical to rapidly adapt to complex crises, organizing proactive medical responses when facing natural or human-made disasters [29].

The $2009 \mathrm{H} 1 \mathrm{~N} 1$ pandemic revealed that communication dynamics are vital for crisis management, and the use of practical tools for the transmission of health recommendations increases compliance [30]. Social media and online resources are now used by more than 3.8 billion, Twitter, and other social media channels can be a reliable source of health-related information [31]. The COVID-19 pandemic has demonstrated that emergency surgical teams and healthcare bodies could use online tools to disseminate guidelines and maintain communication in times of uncertainty [32]. Our study reveals the use of these tools by $91 \%$ of the respondents and the utilization of video conferences by $66 \%$ to improve communication between team members during social distancing. They also had to adapt to new roles when they were assigned to the emergency department triage, ICU, or the management of mechanically ventilated patients, $60 \%$ had to endure long working shifts, and $52 \%$ had $24 \mathrm{~h}$ or more in extremely stressful situations.

Focusing on PPE, current literature reports that there are four essential elements regarding PPE: training, availability, adequate use, and re-use strategies in case of shortage [33-36]. Our study reflects that following PPE recommendations had been a significant issue among respondents; over half expressed concerns for insufficient training, $71 \%$ have reported shortages, and 53\% improvised part of their protective equipment. Training of proper donning/doffing techniques is essential, it will lower the probability of selfcontamination, and educational campaigns must emphasize biosafety breaches to reduce surgical team members' exposure to it [37-40]. A critical shortage of N95/FPP2/3 respirators was reported. This can be explained by the underestimation of equipment needs, coupled with the abrupt increase of its global demand. A recent survey about PPE supplies in the US reported that $91 \%$ of the 213 queried cities had 
inadequate face mask supplies, and $88 \%$ did not have enough PPE for medical personnel and first responders [41]. Tabah et al. in a recent international survey among 2711 intensive care unit healthcare workers, reported widespread shortage and adverse re-use [42]. Another aspect that stands out in our study is that over half $(53 \%)$ of the population had to improvise PPE, undermining front-line workers' trust and confidence with their employer institutions [43]. Additionally, equipment shortage, re-use, and improvisation elevate the risk of infection, adding to the sense of hazardous exposure, and increasing work-associated stress.

Concerning the operating conditions, $71 \%$ had prepared $\mathrm{COA}$ and most followed guidelines to adapt the existing conditions to the suggested recommendations [3]. Information regarding negative pressure OR suites was not addressed in the survey, but if available, negative pressure ORs should be used to reduce the risk of viral spread and minimize infection risk [44]. One element that should be pointed out is the management of surgical smoke during the pandemic. At the beginning of the COVID-19 outbreak, many guidelines recommended avoiding laparoscopy due to the possibility of viral aerosolization and team infection due to smoke inhalation. Current publications have downsized these risks with measures of smoke/aerosol containment and proper smoke evacuation. However, only $26 \%$ reported to have purposed design smoke evacuation systems, and almost half had to improvise them using standard filters, and waters seal devices [45], which could be useful for smoke and vapors generated electrosurgical and ultrasonic devices until more evidence-based research in this field is available.

Reported results of anesthesiologic protocol adoption by the emergency surgery teams reflect a significant lack of implementation of the official recommendations promoted by international anesthesia societies [46, 47]. Our results suggest that improvements must be addressed, especially with equipment preparation during airway manipulation. The importance of having prepared an individual COVID-19 airway trolley with printed airway guidelines should not be underestimated. We consider these elements essential since the use of PPE in the OR has been associated with communication interference and visibility impairment [47]. Using a specific trolley with printed instructions would help avoid errors and reduce team members' risks. Because of the limited number of questions in this area and the reduced number of anesthetists participating in our study, we consider our finding as limited and that further analysis is needed.

Answers received about the operative management reflect the existing differences in the number of new COVID19-positive registered cases in the participating countries during the studied period. During April 2020, the number of new cases was counted by the thousands in several European countries, with Spain and Italy among them, while in America, it was only starting to be diagnosed. Despite these differences, $44 \%$ of the respondents had performed emergency surgery on COVID-19-positive patients. It is essential to highlight the need to use aerosol-generating procedures (AGP) checklists in all emergency surgical procedures. Soma et al. describe how an operative team checklist can potentially reduce risks, but above all, it reduces anxiety and helps maintain the team focused on the task [48]. Results reflect the concerns with the laparoscopic approach and the risks of viral aerosolization. In our study, only $26 \%$ had performed laparoscopic procedures [49]. The low level of reported preoperative COVID-19 screening (32\%) is of serious concern, and efforts should be made to perform some screening for all emergency surgical cases.

Our study had some limitations that must be noted. First, the 2-week period studied reflected a global snapshot of the pandemic, and the number of newly reported cases between Asia, Europe, and America has not been homogeneous. Second, the level of the reported adoptions of the continually changing recommendations reflects respondents' perceptions and opinions, which may not accurately represent actual practices. Confirmation of the reported findings should be audited in future studies. This is particularly important with PPE since the massive demand worldwide had generated a global shortage of some equipment. Also, the survey design might have introduced some bias and had a relatively small sample size. Only $20 \%$ of the contacted participants; this is especially important regarding the small number of anesthetists included in the study $(n=6)$. Finally, our sampling strategy recruited mostly European and American respondents, with very few emergency surgeons from Asia and the Middle East, so that results may be biased. Despite these limitations, the findings reflect the leadership and level of involvement of surgical teams during the pandemic. It identifies the urgent need for more training and better endowment of PPE among emergency surgical teams worldwide. The addressing of these issues will allow better preparation for future similar scenarios and guarantee a better response in case of a second wave of the pandemic to be registered in the coming months.

\section{Conclusion}

Respondents exercised leadership through the development of surgical protocols and safety measures. Social media and video conferences resulted in capital importance for accessing reliable clinical management guidelines and for team communication while maintaining social distancing. Urgent measures to assure sufficient availability of PPE shortage, particularly N95/FPP2/3 respirators must be addressed by healthcare administrators and governments. Even though operative room preparation was adequate, very few had a specific COVID-19 airway trolley at their 
institution; improvements in airway management equipment are advisable.

Acknowledgments We would like to acknowledge all the members of the International Cooperation Group of Emergency Surgery during the COVID-19: Issa Talal (Surgery Department, Royo Villanova Hospital, Zaragoza, Spain), Juan Pablo Ramos, MD (Surgery Department, Sótero del Río Healthcare Complex, Santiago, Chile), Pablo Ottolino (Surgery Department, Sótero del Río Healthcare Complex, Santiago, Chile), Elena Rangelova, MD (Stockholm, Sweden). Our special recognition to all emergency surgical teams around the world for their dedication and efforts during this COVID-19 outbreak. Thanks also to Mercedes Muñoz, information specialist, for her assistance performing a literature search, Carlos Yánez Sr., Ph.D. for his revision, and Ilaria Bondi, medical illustrator.

Author contributions All authors meet authorship criteria for this manuscript as described below. The communication was conceived by CY, AG, HA, and JLB. The literature search was performed by CY, MR, SF, MA. The manuscript draft was written by CY, MR, SDS. LP. Critical revision was done by AG, MR, HA, SF, MA, SDS, LP, AG, and $\mathrm{CM}$. All authors reviewed and approved the final manuscript.

Funding None.

\section{Compliance with ethical standards}

Conflict of interest Carlos Yánez Benítez, Marcelo Ribeiro, Henrique Alexandrino, Piotr Koleda, Sérgio Faria Baptista, Mohammad Azfar, Salomone Di Saverio, Luca Ponchietti, Antonio Güemes, Juan L Blas, and Carlos Mesquita have no conflict of interest.

Ethical standards This article does not contain any studies involving human or animal participants performed by any of the authors.

Availability of data and material The data that support the findings of this study are available from [SurveyMonkey ${ }^{\circledR}$ online platform, SVMK Inc, San Mateo, USA] but restrictions apply to the availability of these data, which were used under license for the current study during the study period, and so are not publicly available. Data are however available from the authors upon reasonable request and with permission of [SurveyMonkey ${ }^{\circledR}$ ].

\section{References}

1. Lu H, Stratton CW, Tang YW. Outbreak of pneumonia of unknown etiology in Wuhan, China: The mystery and the miracle. J Med Virol. 2020;92(4):401-2. https://doi.org/10.1002/jmv.25678.

2. World Health Organization. WHO Director-General's opening remarks at the media briefing on COVID-19 - 11 March 2020. Available from URL: https://www.int/dg/speeches/detail/whodirector-general-s-opening-remarks-at-the-media-briefing-oncovid-19-19--11. (Accessed June 2020)

3. Coccolini F, Perrone G, Chiarugi M, et al. Surgery in COVID19 patients: operational directives. World J Emerg Surg. 2020;15(1):25. https://doi.org/10.1186/s13017-020-00307-2. (Published 2020 Apr 7).

4. De Simone B, Chouillard E, Di Saverio S, et al. Emergency surgery during the COVID-19 pandemic: what you need to know for practice. Ann R Coll Surg Engl. 2020;102(5):323-32. https://doi. org/10.1308/rcsann.2020.0097.
5. Coimbra R, Edwards S, Kurihara H, et al. European Society of Trauma and Emergency Surgery (ESTES) recommendations for trauma and emergency surgery preparation during times of COVID-19 infection. Eur J Trauma Emerg Surg. 2020;46(3):50510. https://doi.org/10.1007/s00068-020-01364-7.

6. Intercollegiate General Surgery Guidance on COVID-19 UPDATE. https://www.rcsed.ac.uk/news-public-affairs/ news/2020/march/intercollegiate-general-surgery-guidance-oncovid-19-update. (Accessed June 2020)

7. American College of Surgeons releases recommendations for surgical management of elective operations during COVID-19 pandemic. https://www.facs.org/about-acs/covid-19/informatio n-for-surgeons. (Accessed June 2020)

8. SAGES and EAES recommendations regarding surgical response to COVID-19 crisis. Released 3/30/2020. https://www.sages.org/ recommendations-surgical-response-covid-19/. (Accessed June 2020)

9. Royal College of Surgeon Coronavirus (COVID-19). Guidance for surgeons working during the COVID-19 pandemic https:// www.rcseng.ac.uk/coronavirus/joint-guidance-for-surgeons-v1/. (Accessed June 2020)

10. Manejo quirúrgico de pacientes con infección por COVID-19. Recomendaciones de la Asociación Española de Cirujanos. https ://www.aecirujanos.es/files/noticias/152/documentos/Manejo_ quirurgico_v2(1).pdf (Accessed June 2020)

11. Aranda-Narváez JM, Tallón-Aguilar L, Pareja-Ciuró F, et al. Emergency surgery and trauma care during COVID-19 pandemic recommendations of the spanish association of surgeons. Cir Esp. 2020;9(20):301688. https://doi.org/10.1016/j.ciresp.2020.04.031. (Published online ahead of print, 2020 Apr 29).

12. American Association for the Surgery of Trauma. COVID-19 Resources. https://www.aast.org/covid-19-resources (Accessed June 2020)

13. Cook TM, El-Boghdadly K, McGuire B, McNarry AF, Patel A, Higgs A. Consensus guidelines for managing the airway in patients with COVID-19: guidelines from the difficult airway society, the association of anaesthetists the intensive care society, the faculty of intensive care medicine and the royal college of anaesthetists. Anaesthesia. 2020;75(6):785-99. https://doi.org/10.1111/ anae. 15054.

14. Flemming S, Hankir M, Ernestus RI, et al. Surgery in times of COVID-19-recommendations for hospital and patient management. Langenbecks Arch Surg. 2020;405(3):359-64. https://doi. org/10.1007/s00423-020-01888-x.

15. Mitura K, Myśliwiec P, Rogula W, et al. Guidelines for the management of surgical departments in non-uniform hospitals during the COVID-19 pandemic. Pol Przegl Chir. 2020;92(2):48-59. https://doi.org/10.5604/01.3001.0014.1039.

16. Di Saverio S, Pata F, Gallo G, et al. Coronavirus pandemic and colorectal surgery: practical advice based on the Italian experience. Colorectal Dis. 2020;22(6):625-34. https://doi.org/10.1111/ codi. 15056.

17. Coccolini F, Catena F, Pisano M, et al. (2015) Open versus laparoscopic cholecystectomy in acute cholecystitis Systematic review and meta-analysis [published correction appears. Int J Surg. 2015;18:196-204. https://doi.org/10.1016/j.ijsu.2015.04.083.

18. Patriti A, Baiocchi GL, Catena F, Marini P. Catarci M (2020) FACS on behalf of the Associazione Chirurghi Ospedalieri Italiani (ACOI). Emergency general surgery in Italy during the COVID-19 outbreak: first survey from the real life. World J Emerg Surg. 2020;15(1):36. https://doi.org/10.1186/s13017-020-00314 -3 .

19. Guan WJ, Ni ZY, Hu Y, Liang WH, Ou CQ, He JX, et al. China medical treatment expert group for Covid-19. Clinical characteristics of coronavirus disease 2019 in China. N Engl J Med. 2020. https://doi.org/10.1186/s13017-020-00314-3. 
20. Aminian A, Safari S, Razeghian-Jahromi A, Ghorbani M, Delaney CP. COVID-19 outbreak and surgical practice: unexpected fatality in perioperative period. Ann Surg. 2020. https://doi.org/10.1097/ SLA.0000000000003925.

21. Angelos G, Dockter AG, Gachabayov M, Latifi R, Bergamaschi R. Emergency colorectal surgery in a COVID-19 pandemic epicenter. Surg Technol Int. 2020;36:18-211.

22. Pini Prato A, Conforti A, Almstrom M, et al. Management of COVID-19-positive pediatric patients undergoing minimally invasive surgical procedures: systematic review and recommendations of the board of european society of pediatric endoscopic surgeons. Front Pediatr. 2020;8:259. https://doi.org/10.3389/ fped.2020.00259.

23. Patriti A, Eugeni E, Guerra F. What happened to surgical emergencies in the era of COVID-19 outbreak? Considerations of surgeons working in an Italian COVID-19 red zone. Updates Surg. 2020. https://doi.org/10.1007/s13304-020-00779-6 (published online ahead of print, 2020 Apr 23).

24. Xu S, Li Y. Beware of the second wave of COVID-19. Lancet. 2020;395(10233):1321-2. https://doi.org/10.1016/S0140 $-6736(20) 30845-X$

25. Ali I. COVID-19: are we ready for the second wave? Disaster Med Public Health Prep. 2020. https://doi.org/10.1017/dmp.2020.149 (published online ahead of print, 2020 May 7).

26. Wise J. Covid-19: Risk of second wave is very real, say researchers. BMJ. 2020;369:2294. https://doi.org/10.1136/bmj.m2294.

27. Zizzo M, Bollino R, Castro Ruiz C, et al. Surgical management of suspected or confirmed SARS-CoV-2 (COVID-19)-positive patients: a model stemming from the experience at level III hospital in Emilia-Romagna. Italy Eur J Trauma Emerg Surg. 2020;46(3):513-7. https://doi.org/10.1007/s00068-020-01377-2.

28. Lancaster EM, Sosa JA, Sammann A, et al. Rapid response of an academic surgical department to the COVID-19 pandemic: implications for patients, surgeons, and the community. J Am Coll Surg. 2020;230(6):1064-73. https://doi.org/10.1016/j.jamcollsur g.2020.04.007.

29. Briggs SM. Responding to crisis: surgeons as leaders in disaster response. J Am Coll Surg. 2017;225(6):691-5. https://doi. org/10.1016/j.jamcollsurg.2017.08.025.

30. Scarcella C, Antonelli L, Orizio G, et al. Crisis communication in the area of risk management: the CriCoRM project. J Public Health Res. 2013;2(2):e20. https://doi.org/10.4081/jphr.2013.e20. (Published 2013 Sep 20).

31. Cuello-Garcia C, Pérez-Gaxiola G, van Amelsvoort L. Social Media can have an impact on how we manage and investigate the COVID-19 pandemic. J Clin Epidemiol. 2020;4356(20):30652. https://doi.org/10.1016/j.jclinepi.2020.06.028. (published online ahead of print, $2020 \mathrm{Jun} 27$ ).

32. Stokel-Walker C. Covid-19: the doctors turned YouTubers. BMJ. 2020;369:1563. https://doi.org/10.1136/bmj.m1563. (Published 2020 May 28)

33. World Health Organization. (2020). Rational use of personal protective equipment for coronavirus disease (COVID-19) and considerations during severe shortages: interim guidance, 6 April 2020. World Health Organization. https://apps.who.int/iris/handl e/10665/331695. (Accessed June 2020)

34. Center for Disease Control and Prevention C Recommended Guidance for Extended Use and Limited Reuse of N95 Filtering Facepiece Respirators in Healthcare Settings. https://www. cdc.gov/niosh/topics/hcwcontrols/recommendedguidanceextuse .html (Accessed June 2020)

35. Wang J, Zhou M, Liu F. Reasons for healthcare workers infected with novel coronavirus disease 2019 (COVID-19) in China. J Hosp Infect. 2020;105(1):100-1. https://doi.org/10.1016/j. jhin.2020.03.002.
36. Yorio PL, Fisher EM, Kilinc-Balci FS, et al. Planning for epidemics and pandemics: assessing the potential impact of extended use and reuse strategies on respirator usage rates to support supply-and-demand planning efforts. J Int Soc Respir Prot. 2020;37(1):52-60.

37. Muñoz-Leyva F, Niazi AU. Common breaches in biosafety during donning and doffing of protective personal equipment used in the care of COVID-19 patients. Can J Anaesth. 2020;67(7):900-1. https://doi.org/10.1007/s12630-020-01648-x.

38. World Health Organization (2020) Infection prevention and control during health care when novel coronavirus (nCoV) infection is suspected. Interim guidance. https://www.who.int/publications/i/ item/10665-331495 (Accessed June 2020)

39. Lee I-K, Wang C-C, Lin M-C, Kung C-T, Lan K-C, Lee C-T. Effective strategies to prevent coronavirus disease-2019 (COVID19) outbreak in hospital. J Hosp Infect. 2020;105(1):102-3. https ://doi.org/10.1016/j.jhin.2020.02.022.

40. The Lancet COVID-19. protecting health-care workers. Lancet. 2020;395(10228):922. https://doi.org/10.1016/S0140 $-6736(20) 30644-9$.

41. Kamerow D. Covid-19: the crisis of personal protective equipment in the US. BMJ. 2020;369:1367. https://doi.org/10.1136/ bmj.m1367(Published 2020 Apr 3).

42. Tabah A, Ramanan M, Laupland KB, et al. (2020) Personal protective equipment and intensive care unit healthcare worker safety in the COVID-19 era (PPE-SAFE): an international survey. J Crit Care. 2020;59:70-5. https://doi.org/10.1016/j.jcrc.2020.06.005. (Published online ahead of print, 2020 Jun 13).

43. O'Sullivan ED. PPE guidance for covid-19: be honest about resource shortages. BMJ. 2020;369:1507. https://doi.org/10.1136/ bmj.m1507. (Published 2020 Apr 17).

44. Wong J, Goh QY, Tan Z, et al. Preparing for a COVID-19 pandemic: a review of operating room outbreak response measures in a large tertiary hospital in Singapore. Se préparer pour la pandémie de COVID-19: revue des moyens déployés dans un bloc opératoire d'un grand hôpital tertiaire au Singapour. Can J Anaesth. 2020;67(6):732-45. https://doi.org/10.1007/s12630-02001620-9.

45. MIS Filtration Group. How to manage smoke evacuation and filter pneumoperitoneum during laparoscopy to minimize potential viral spread: different methods from SoMe - a video vignette. Colorectal Dis. 2020;22(6):644-5. https://doi.org/10.1111/codi.15086.

46. American Society of Anesthesiologist. COVID-19 Information for Health Care Professionals. https://www.asahq.org/about-asa/ governance-and-committees/asa-committees/committee-on-occup ational-health/coronavirus (Accessed June 2020)

47. Canadian Anesthesiologists' Society. COVID-19 Recommendations during Airway Manipulation. https://www.cas.ca/CASAs sets/Documents/News/Updated-March-25-COVID-19_CAS_ Airway_Vsn_4.pdf(Accessed June 2020)

48. Yánez Benítez C, Güemes A, Aranda J, et al. Impact of personal protective equipment on surgical performance during the COVID19 pandemic. World J Surg. 2020;2:1-6. https://doi.org/10.1007/ s00268-020-05648-2. (Published online ahead of print, 2020 Jun 20).

49. Soma M, Jacobson I, Brewer J, Blondin A, Davidson G, Singham $\mathrm{S}$. Operative team checklist for aerosol generating procedures to minimise exposure of healthcare workers to SARS-CoV-2. Int J Pediatr Otorhinolaryngol. 2020;134:110075. https://doi. org/10.1016/j.ijporl.2020.110075.

50. Pavan N, Crestani A, Abrate A, et al. Risk of virus contamination through surgical smoke during minimally invasive surgery: a systematic review of literature on a neglected issue revived in the COVID-19 pandemic era. Eur Urol Focus. 2020;4569(20):3015665 (published online ahead of print, 2020 Jun 5). 


\section{Affiliations}

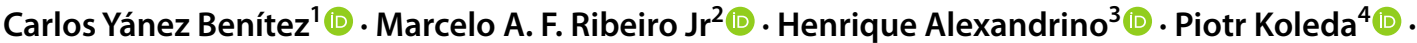

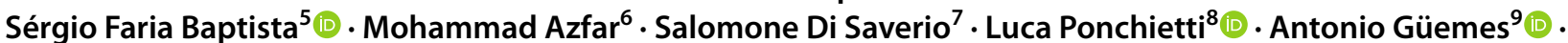 Juan L. Blas ${ }^{1} @$. Carlos Mesquita ${ }^{3}$}

Marcelo A. F. Ribeiro Jr

drmribeiro@gmail.com

Henrique Alexandrino

halexandrino123@gmail.com

Piotr Koleda

piotr.koleda@umed.wroc.pl

Sérgio Faria Baptista

sergiofariabatista@gmail.com

Mohammad Azfar

mazfar@gmail.com

Salomone Di Saverio

salo75@inwind.it

Luca Ponchietti

lponchietti@salud.aragon.es

Antonio Güemes

aguemes@unizar.es

Juan L. Blas

julublas@gmail.com

Carlos Mesquita

mesquita.carlos@sapo.pt

1 General and GI Surgery Department, Royo Villanova Hospital, SALUD, Av. de San Gregorio s/n. 50015,

Zaragoza, Spain
2 Department of General Surgery and Trauma Surgery, Catholic University of São Paulo PUC-Sorocaba and Hospital Moriah, Avenida Victor Civita, Sao Paulo 235, Brazil

3 Department of General Surgery, Faculty of Medicine, Coimbra University Hospital Center, University of Coimbra, Praceta Mota Pinto, 3000-045 Coimbra, Portugal

4 Department of Medical Simulation, Faculty of Medicine, Wroclaw Medical University, Wroclaw, Poland

5 Department of Anesthesiology, Centro Hospital do Médio Tejo, EPE, Tomar, Portugal

6 Department of General Surgery, Al Rahba Hospital, Abu Dhabi, UAE

7 Department of General Surgery, Varese University Hospital, ASST Sette Laghi, University of Insubria, Regione Lombardia, Varese, Italy

8 Department of General Surgery, San Jorge University Hospital, Av. Martínez de Velasco, 36, 22004 Huesca, Spain

9 Department of General Surgery, Lozano Blesa University Hospital, Av. San Juan Bosco, 15, 50009 Zaragoza, Spain 